\title{
Analysis of the causes of damage to the RC floor slab in the underground garage
}

\author{
Piotr Matysek ${ }^{1, *}$, and Michat Witkowski ${ }^{1}$ \\ ${ }^{1}$ Cracow University of Technology, 24 Warszawska Str., 31-155, Cracow, Poland
}

\begin{abstract}
The article presents the results of testing a damaged reinforced concrete slab, which is located in the underground garage constituting the two lowest floors of a residential and service building. During the tests numerous cracks in the slab were inventoried. Some cracks covered the entire thickness of the RC slab and floor layers made of synthetic resin. The result of these damages was penetration through the slab of water from molten slush and the need to limit the parking places on the lower level of the garage. Conducted analysis of technical documentation, analysis of damage morphology, control material tests and structure computations allowed assessment of the causes of existing damages to the floor slab and ability to develop recommendations regarding the methods of its repair.
\end{abstract}

\section{Introduction}

The underground garages, which are located under buildings, are a typical solution for the intensive development of plots in the cities. Most often, these objects are realized with a monolithic reinforced concrete structure. Proper design and construction allow for a longterm and cheap exploitation. Often, however, mistakes made at the design and/or execution stage of garage buildings limit their use and may even cause lowering load capacity of the structure $[1,2]$. A frequent cause of exploitation problems is leaks in vertical partitions (walls) and horizontal partitions (floor slabs, foundation slabs). These leaks result from improper performance of damp insulation. The direct effect of faulty damp insulation is the penetration of ground or rainwater into the interior of garage facilities. In multi-level garages, leaking inter-story floors are not a barrier to aggressive waters arising from melting slush, which is brought in by parked cars. Currently, a popular solution is to build underground garages with waterproof concrete technology. The execution of a reinforced concrete structure with this technology requires proper selection of materials and technology. Errors in this area result in crack formation in $\mathrm{RC}$ walls, floor slabs, and foundation slabs, and lack of tightness of partitions. The article presents a floor slab in an underground garage which was incorrectly designed and built. There were numerous cracks in the slab. Part of them included the entire thickness of the slab and the floor layer made on the structure. The result of cracks was the dampness of the reinforced concrete structure and cars parked under the floor slab are affected by slush waters containing aggressive chlorides from de-icing agents.

\footnotetext{
*Corresponding author: pmatysek@pk.edu.pl
} 
Leaks caused damage to paint coatings in cars. In the long term, the action of water containing chlorides can lead to intense corrosion processes and structure failure.

\section{Characteristics of the floor slab and the method of its execution}

The RC slab, which is the subject of this article, separates two floors of an underground garage located in a residential and service building. The building was realized as an object with 11 floors, placed directly on the supporting ground using the foundation slab. The structure of the building was made as a monolithic reinforced concrete. The floor slab of the garage is based directly on reinforced concrete walls and pillars. In the contour, the floor slab at level $-2.9 \mathrm{~m}$ has the shape of an irregular polygon, with external dimensions $18.5 \times 32.0 \mathrm{~m}$. There are two drain holes in the slab for drainage of water that can accumulate on its upper surface. Under the slab, the installations required in garage facilities were suspended.

The project assumed the use of a $\mathrm{C} 30 / 37$ class of concrete and reinforcement with bars of diameters from $10 \mathrm{~mm}$ to $25 \mathrm{~mm}$ in the spacing of $150 \mathrm{~mm}$ and $200 \mathrm{~mm}$. No upper reinforcement in the spans was provided. It was recommended in the project that declines should be developed in the RC slab above the level -2.9 and the thickness of the slab cannot be less than $250 \mathrm{~mm}$. The limit value of the crack width, was assumed at $0.2 \mathrm{~mm}$, however, with respect to deflections, a limit value of $30 \mathrm{~mm}$ has been assumed.

The floor slab was concreted at the end of September. The $250 \mathrm{~mm}$ thick plate was poured, and then the declines were formed using the "wet on wet" method. From the construction documents it did not appear that reinforcement was laid in decline concrete layers. Taking into account the declines in the floor slab and the distance from the outflows to the walls, it can be assessed that the thickness of the slab near to the walls is approx. $100 \mathrm{~mm}$ higher than at the outflows.

Before the floor layers were made, cracks in the slab were found. The construction documents did not record their location or widths. Despite the cracks, which had been found in the slab, it was decided to put a resin floor directly on the upper surface of the RC slab.

\section{Tests of the structure}

\subsection{Description of the damages}

Research was carried out about 2.5 years from the moment of slab execution. During the local viewings, numerous cracks were seen in the garage slab. Cracks were visible on the lower and upper surface of the slab. Cracks on the upper surface also included the floor layer. The directions of the cracks were varied and their widths were up to $0.5 \mathrm{~mm}$. The larges widths had cracks in the passage band. The morphology of the cracks inventoried on the bottom and on the upper surfaces of the slab is presented in Fig. 1, while the character of typical cracks is shown in Fig. 2. The course of some cracks on the bottom and upper surfaces of the floor slab was similar, which proved that the slab was cracking over its entire thickness. In the cracks, which were visible on the bottom slab surface, numerous effects of intensive salt crystallization were found. Cracks on the upper surface of the slab were visible on the resin floor layer, which was made directly on the reinforced concrete structure. Some of the cracks showed visible traces of earlier repairs. 


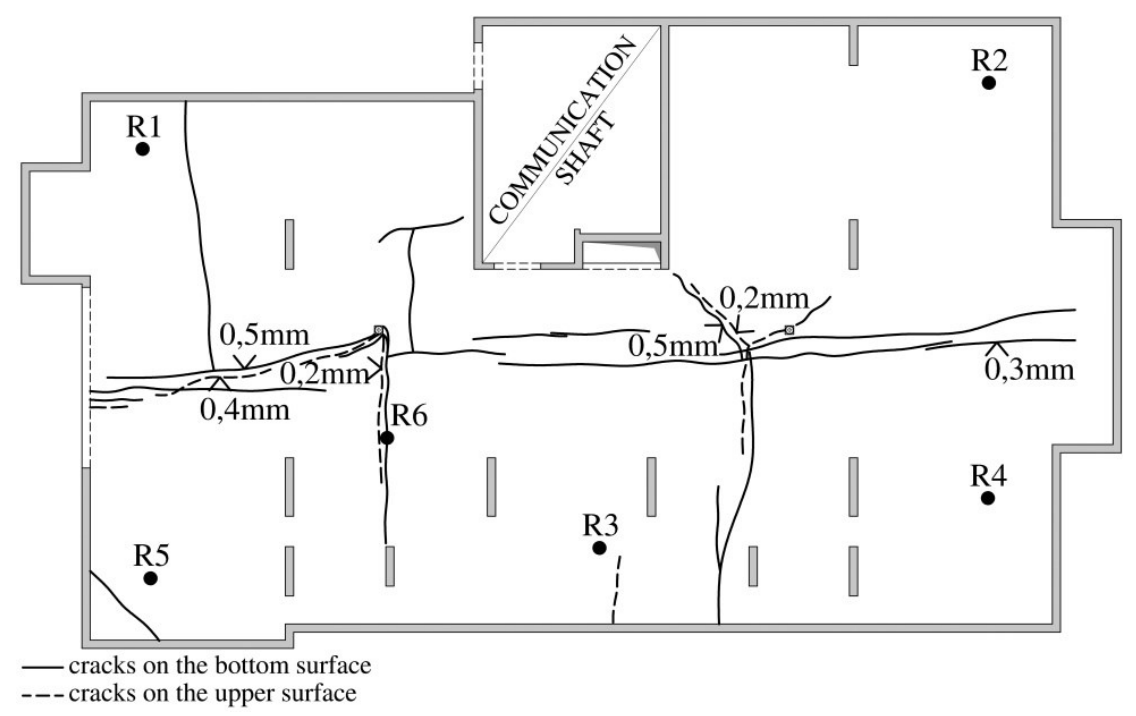

Fig. 1. The morphology of cracks on the bottom and on the upper surfaces of the slab.

a)

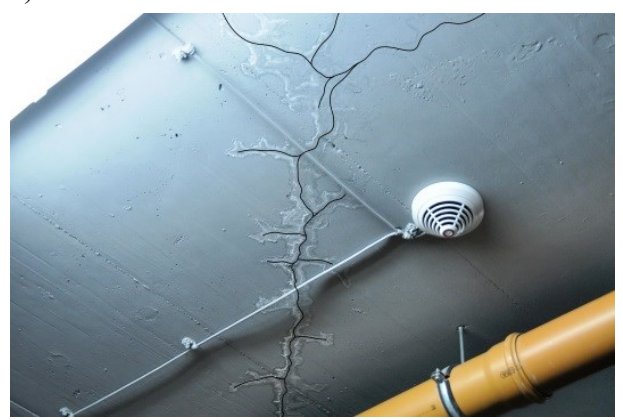

b)

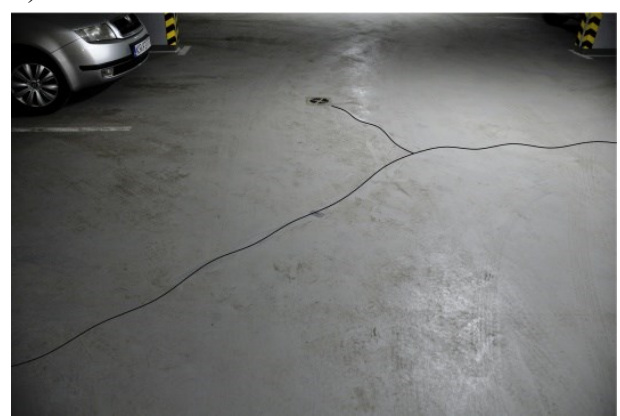

Fig. 2. Examples of floor cracks visible on its bottom (a) and upper (b) surfaces.

\subsection{Tests of samples extracted from the structure}

Six cylindrical samples with a diameter of $114 \mathrm{~mm}$ were cut from the RC slab. Sampling places are marked in Fig. $1(\mathrm{R} 1-\mathrm{R} 6)$. Some of the core samples were made to the level of bottom reinforcement. The core sample No. 6 was made in the place of the crack, which could be observed on the upper surface of the floor. After a detailed inventory of the core samples, 5 of them were cut out to carry out the strength tests. The view of core samples before and after cutting is shown in Fig. 3. The results of tests were presented in Table 1 .

The $R 1 / 1 \div R 5 / 1$ samples originate from the top of the cores, while samples $R 1 / 2 \div R 5 / 2$ from their lower fragments. The mean concrete strengths determined on the samples from the upper and lower parts of the cores differ slightly $(8.4 \%)$. A very small difference also exists between the minimum values of compressive strength of concrete $(2.2 \%)$. The coefficient of variation (COV) of compressive strength of concrete does not exceed $10 \%$. In the cores, there were no traces of discontinuities in the structure (horizontal scratches, cracks, splices) between concretes laid at different times. 
a)

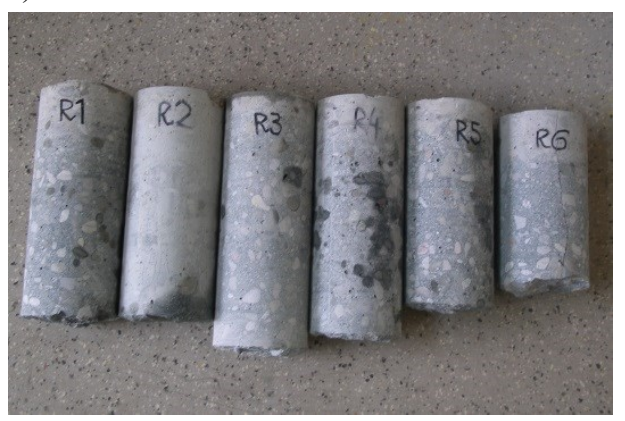

b)

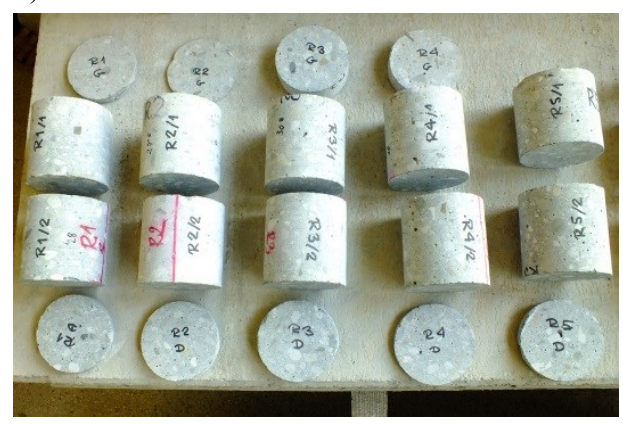

Fig. 3. Cylindrical samples cut from the RC slab - view of samples before cutting (a), samples after cutting (b).

Table 1. The results of compressive strength tests of concrete.

\begin{tabular}{|l|c|c|c|}
\hline Marking of samples & $\begin{array}{c}\text { The range of values } \\
{[\mathrm{MPa}]}\end{array}$ & $\begin{array}{c}\text { Mean value } \\
{[\mathrm{MPa}]}\end{array}$ & $\begin{array}{c}\mathrm{COV} \\
{[\%]}\end{array}$ \\
\hline $\mathrm{R} 1 / 1 \div \mathrm{R} 5 / 1$ samples & $51.4 \div 58.6$ & 54.5 & 5.4 \\
\hline $\mathrm{R} 1 / 2 \div \mathrm{R} 5 / 2$ samples & $50.4 \div 63.4$ & 59.1 & 9.2 \\
\hline
\end{tabular}

The results presented in Table 1 are the compressive strengths of concretes on the day of testing. The tests were carried out 2.5 years from the moment of concreting the floor slab. The PN-EN 1992-1-1 [3] standard specifies the relationship to determine the increase in the strength of concrete over time:

$$
\beta_{c c}=\exp \left[s\left(1-\sqrt{\frac{28}{t}}\right)\right]
$$

where $t$ is time from the moment of concreting, $s$ is a factor depending on the type of cement.

Based on this relationship, it can be evaluated that after 2.5 years, the concrete strength increase was about $37 \%$. After taking into account this coefficient and converting results in accordance with PN-EN 13791: 2008 [4] standard, the characteristic compressive strengths of concrete were as $32.9 \mathrm{MPa}$ and $36.2 \mathrm{MPa}$, respectively. This allowed qualification of the concrete in the RC slab to class $\mathrm{C} 30 / 37$.

In the R6 sample, the crack ran all over its height and had a similar width at the top and bottom of the sample.

No reinforcement bars were found at the upper edge in any of the tested core samples. On the basis of traces of bottom reinforcement in the core samples, it was found that the diameter of the bottom reinforcement bars was $10 \mathrm{~mm}$ and it was compatible with the bar diameters assumed in these locations in the project.

\subsection{Complementary research}

During the inspection, control tests were also carried out using the N-type Schmidt hammer. The tests were carried out in 6 places on the bottom surface of the floor slab. The Schmidt hammer rebound numbers achieved in the examined points were obtained ranging from 42.3 to 47.0 . The homogeneity of concrete in the structure of the slab was rated as very good (coefficient of variation of $8 \%$ ). 
Also, the measurements of the spacing of reinforcing bars using the magnetic scanning method on the bottom surface of the slab were carried out. The mean spacing of bars measured in the tests differed no more than $5 \%$ from those assumed in the design.

\section{Control calculations}

\subsection{Minimum reinforcement in the floor slab}

The minimum tensile reinforcement for the floor slab subjected to bending is shown in Table 2. This reinforcement was determined in accordance with PN-EN 1992-1-1 [3] and PN-B-03264: 2002 [5] standards, from the formulas:

$$
\begin{aligned}
& A_{s, \min }^{(1)}=0,0013 b d \\
& A_{s, \min }^{(2)}=0,26 \frac{f_{c t m}}{f_{y k}} b d \\
& A_{s, \min }^{(3)}=k_{c} k f_{c t, e f f} \frac{A_{c t}}{\sigma_{s}}
\end{aligned}
$$

where $b, d$ are width of a cross section and effective depth of a cross-section respectively, $f_{c t m}$ is mean tensile strength of concrete, $f_{y k}$ is characteristic yield strength of reinforcement, $k_{c}$ is a coefficient which takes into account the stress distribution within the section immediately prior to cracking and of the change of the lever arm, $k$ is the coefficient which allows for the effect of non-uniform self-equilibrating stresses, which lead to a reduction of restraint forces, $\sigma_{s}$ is the stress permitted in reinforcement immediately after formation of the crack.

The minimum reinforcements calculated in accordance with PN-B-03264: 2002 [5] are presented in brackets. Minimum reinforcements $A_{s, \min }{ }^{(3 a)}, A_{s, \min }{ }^{(3 b)}$ were calculated with the assumption of the limiting crack width of $0.2 \mathrm{~mm}$ and $0.3 \mathrm{~mm}$, respectively. The limiting crack width $0.3 \mathrm{~mm}$ was accepted to calculations because PN-EN 1992-1-1 standard [3] allows this value for the exposure class XD3. The $A_{s, \min }{ }^{(3 c)}$ are the minimum reinforcements determined on the assumption that stresses in the tension bars will reach the value of the characteristic yield strength of the steel. The $A_{s, \min }{ }^{(3 c)}$ values were given comparatively.

Table 2. Minimum reinforcement in the floor slab subjected to bending.

\begin{tabular}{|c|c|c|c|c|c|}
\hline Thickness [mm] & $\begin{array}{c}A_{\text {smin }}{ }^{(1)} \\
{\left[\mathrm{mm}^{2}\right]}\end{array}$ & $\begin{array}{c}A_{\text {smin }}{ }^{(2)} \\
{\left[\mathrm{mm}^{2}\right]}\end{array}$ & $\begin{array}{c}A_{\text {smin }}^{(3 a)} \\
{\left[\mathrm{mm}^{2}\right]}\end{array}$ & $\begin{array}{c}A_{\text {smin }}{ }^{(3 b)} \\
{\left[\mathrm{mm}^{2}\right]}\end{array}$ & $\begin{array}{c}A_{\text {smin }}{ }^{(3 c)} \\
{\left[\mathrm{mm}^{2}\right]}\end{array}$ \\
\hline$h_{f}=250 \mathrm{~mm}$ & $273(273)$ & $317(317)$ & $558(447)$ & $453(363)$ & $290(232)$ \\
\hline$h_{f}=350 \mathrm{~mm}$ & $403(403)$ & $468(468)$ & $753(608)$ & $612(494)$ & $392(315)$ \\
\hline
\end{tabular}

$k_{c}=0.4 ; f_{c t, e f f}=f_{c t m} ; b=1.0 \mathrm{~m} ; d=0.21 \mathrm{~m} \mathrm{i} 0.31 \mathrm{~m} ; \sigma_{s}$ as for bars with a diameter of $10 \mathrm{~mm} ; k=1.0$ for $h_{f}=250 \mathrm{~mm} ; k=0.965$ [3], $k=0.77$ [5] for $h_{f}=350 \mathrm{~mm}$

Minimum reinforcement in the floor slab due to thermal-shrinkage stresses (see Table 3) was calculated in accordance with PN-EN 1992-1-1 [3] and PN-B-03264 [5], assuming that at the moment of cracking, the tensile strength of concrete is $0.5 f_{\mathrm{ctm}}$ [6]. The values presented in Table 3 refer to the reinforcement at one edge of the slab. The values in the next columns of Table 3 indicate the minimum reinforcement determined by assumption that the widths of 
the cracks formed in the floor slab due to thermal-shrinkage stresses will not exceed the value of $0.2 \mathrm{~mm}\left(A_{s, \min }{ }^{(4 a)}\right)$ and $0.3 \mathrm{~mm}\left(A_{s, m i n}{ }^{(4 b)}\right)$ or it will not be limited $\left(A_{s, \min }{ }^{(4 c)}\right)$.

Table 3. Minimum reinforcement in the floor slab due to thermal-shrinkage effects

\begin{tabular}{|c|c|c|c|}
\hline Thickness [mm] & $\begin{array}{c}A_{s, \min }{ }^{(4 a)} \\
{\left[\mathrm{mm}^{2}\right]} \\
\end{array}$ & $\begin{array}{c}A_{s, \min }{ }^{(4 b)} \\
{\left[\mathrm{mm}^{2}\right]}\end{array}$ & $\begin{array}{c}A_{s, \min }(4 c) \\
{\left[\mathrm{mm}^{2}\right]}\end{array}$ \\
\hline$h_{f}=250 \mathrm{~mm}$ & $1007(558)$ & $824(453)$ & $566(290)$ \\
\hline$h_{f}=350 \mathrm{~mm}$ & $1360(752)$ & $1113(610)$ & 764 (391) \\
\hline \multicolumn{4}{|c|}{$\begin{array}{l}k_{c}=1.0 ; f_{c t, e f f}=0.5 f_{c t m} ; b=1.0 \mathrm{~m} ; d=0.21 \mathrm{~m} \text { and } 0.31 \mathrm{~m} ; \sigma_{s} \text { for bars of the } \\
\text { diameter of } 10 \mathrm{~mm} \text { with a correction due to } f_{c t, e f f}, k=1.0[3], k=0.8[5] \text { for } h_{f}= \\
250 \mathrm{~mm} ; k=0.965[3], k=0.77[5] \text { for } h_{f}=350 \mathrm{~mm}\end{array}$} \\
\hline
\end{tabular}

The minimum reinforcement in the floor slab, calculated on the basis of PN-EN 1992-1-1 [3] standard, is clearly larger than the minimum reinforcement specified in accordance with the recommendations of PN-B-3264 [5] standard. K. Flaga in [7] gave the relationship to determine the reinforcement ratio in zones subjected to cracking due to concrete shrinkage:

$$
0,55 \frac{f_{c t m}}{f_{y k}} \leq \rho_{s s} \leq 1,1 \frac{f_{c t m}}{f_{y k}}
$$

Assuming $f_{c t m}=2.9 \mathrm{MPa}, f_{y k}=500 \mathrm{MPa}$ from the relationship (5) can be obtained following formula:

$$
0,0032 \leq \rho_{s s} \leq 0,00638
$$

In the case of the analyzed floor slab, in which deformations due to thermal-shrinkage effects are limited by fixing the floor slab in reinforced concrete walls, the value of the minimum reinforcement ratio, according to (6) is 0.00638 , which corresponds to $798 \mathrm{~mm}^{2}$ for $h_{f}=250 \mathrm{~mm}$ and $1190 \mathrm{~mm}^{2}$ for $h_{f}=350 \mathrm{~mm}$. This corresponds approximately to the values of $A_{s, \min }{ }^{(4 b)}$ determined in accordance with PN-EN 1992-1-1 [3] assuming the limit cracks width $w_{\text {lim }}=0.3 \mathrm{~mm}$.

\subsection{Static computations}

Static computations were performed for the 3D model of structure shown in Fig. 4. The structural analysis was made for many combinations of actions. The calculations were performed taking into account the imposed load of cars assumed in the project, equal to $3.5 \mathrm{kN} / \mathrm{m}^{2}$ and the load induced by light truck (with a weight of $60 \mathrm{kN}$ ). Taking into account a load of a light truck resulted from the notes in the construction site documents. In these documents it was written that cars of this type would be arriving and parking on the garage slab during the execution phase of the building. 


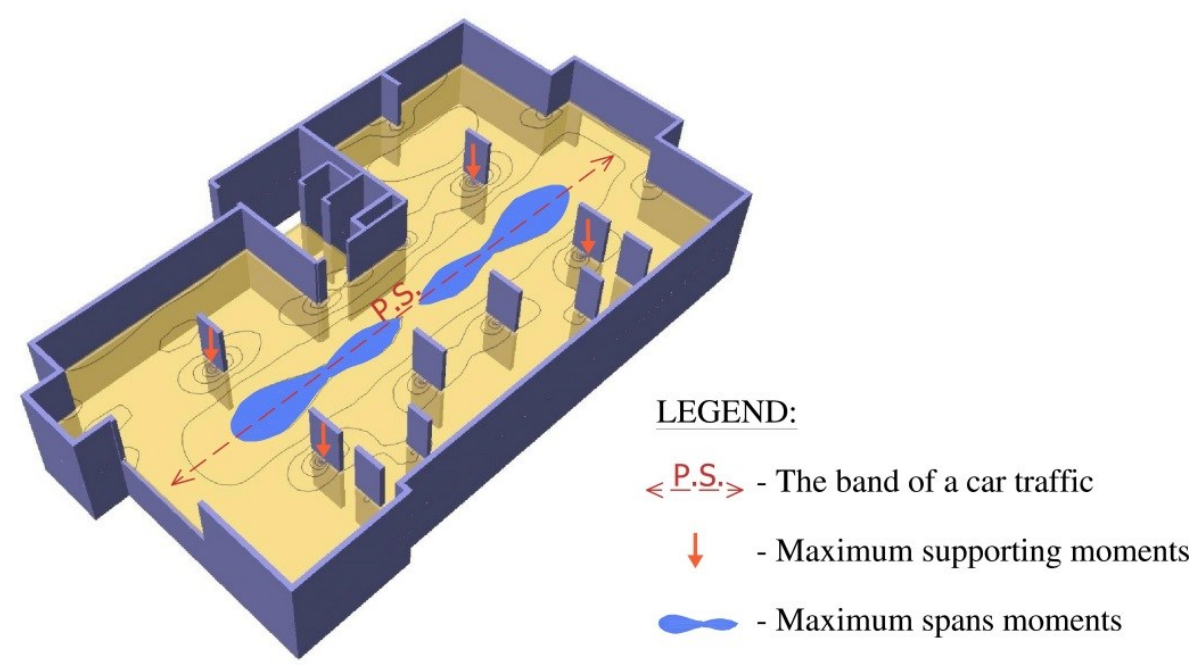

Fig. 4. Structural model.

Based on the calculations, it was found that there is no safety risk resulting from insufficient slab load capacity. The biggest cracks, caused by the combined effect of permanent and imposed loads, are located in the passage band of the floor slab (marked as P.S. in Figure 4). The value of crack widths calculated in accordance with the PN-EN 1992-1-1 [3] standard, did not exceed $0.25 \mathrm{~mm}$. Slightly smaller values of crack widths (about $10 \%$ ) were obtained on the basis of a comparative analysis in accordance with the PN-B-03264: 2002 [5] standard. The obtained values of crack widths should be treated as an estimate. From the technical documents, it was not possible to recreate the location and form of cracks, which had occurred in the slab in the execution period. Cracks of this type affect the rigidity of the floor slab and influence results of static calculations.

\section{Discussion of test and computation results, the proposed repair method}

The width of cracks, which were inventoried in the garage slab, were greater than the limit value adopted in the project of $0.2 \mathrm{~mm}$. Some cracks in the slab had a width of $0.5 \mathrm{~mm}$, which causes, that the requirements of serviceability limit states in terms of limiting the width of cracks are not met. A part of the cracks was created on the slab before making the floor layers and by using the structure as it had been intended. These cracks were created as a result of thermal-shrinkage stresses. The creation of these cracks was fostered by the method of execution of the floor slab and the method of its reinforcement. The slab has been concreted with a thickness of $250 \mathrm{~mm}$, and then, by the wet-on-wet method, the declines to the drains were shaped. In the slab, almost on $90 \%$ of its area, the bottom reinforcement consists of bars with a diameter of $10 \mathrm{~mm}$, spaced every $200 \mathrm{~mm}$ or every $150 \mathrm{~mm}$. The area of the bottom reinforcement is therefore $393 \mathrm{~mm}^{2}$ of the spacing of $200 \mathrm{~mm}$ and $524 \mathrm{~mm}^{2}$ of the spacing of $150 \mathrm{~mm}$. No upper reinforcement was designed in the spans of slab. Upper reinforcement in the spans of the slab was also not found in the 6 tested core samples extracted from the slab structure. Taking into account the values listed in Table 3, it can be stated that the minimum reinforcement, due to thermal-shrinkage effects, was too small to limit the width of cracks up to $0.2 \mathrm{~mm}$. 
Cracks on the upper surface of slab were covered during the resin flooring. Some of these cracks appeared after the floor was made and were visible during the research. This proved the activity of the process of cracks developing during the use of the slab as a garage parking plate. As it was demonstrated by the structural analysis of the slab with applied loads and loads, which had not been assumed in the project but had occurred during the execution works (a load of a light truck) the calculated crack widths also exceed the limit value of $0.2 \mathrm{~mm}$.

Removing the damaged and leaky floor layer made of synthetic resin and then implementing a systemic injection of cracks was recommended. The injection should be made with the materials, which, on the one hand, will seal cracks, and on the other hand will allow slab deformations. The injection materials based on polyurethane were suggested. As the last stage of the repair, making a new floor layer on the slab by using a material that has proper ductility for transferring the cumulative strains, which will be occurring in the region of the slab cracks was recommended.

\section{Summary}

In the paper the results of tests and static analysis of the damaged reinforced concrete floor slab located in an underground garage were presented. The main damage to the slab were cracks with the widths, significantly exceeding the limiting values recommended in standards for concrete structures. Cracks in the reinforced concrete slab also caused the damage to the floor layers. Based on the analysis of the results of the tests and computations, it was found that the cause of the damage were design errors as well as the errors in the execution process of RC slab. In the current technical condition, the floor slab does not constitute a sealed barrier and limits the use of the lower floor of the garage. In the long term, permeation through the floor slab of the slush water containing aggressive chlorides can lead to an intensification of corrosion processes in the structure and lowering its load capacity. Recommendations on the protection and repair of the slab have been given.

\section{References}

1. M. Kałuża, J. Kubica, J. Hulimka, A history of strengthening and repair works of reinforced concrete slab above the garage. (Proceedings of XXVII Scientific-Technical Conference on Structural Failures, Szczecin-Międzyzdroje, pp. 617-624, 2015) [in Polish]

2. P. Przybysz, K. Szulborski, Damaged R/C flat plates on examples of an underground garage (Proceedings of XXVI Scientific-Technical Conference on Structural Failures, Szczecin-Międzyzdroje, pp. 721-726, 2013) [in Polish]

3. PN-EN 1992-1-1: Eurocode 2, Design of concrete structure - Part 1-1: General rules and rules for buildings

4. PN-EN 13791: Assessment of in situ compressive strength in structures and precast concrete components

5. PN-B-03264:2002: Konstrukcje betonowe, żelbetowe i sprężone -- Obliczenia statyczne i projektowanie [in Polish]

6. M. Knauff, B. Grzeszczykowski, A. Golubińska, Przykłady obliczania konstrukcji żelbetowych. Zeszyt 3 (PWN, Warszawa, 2018) [in Polish]

7. K. Flaga, The shrinkage of concrete and its effect on load carrying capacity, serviceability, and durability of reinforced and pre-stressed concrete structures, (Monography No 73, Cracow University of Technology, Cracow, 2002) [in Polish] 